\title{
Music and Environment: From Artistic Creation to the Environmental Sensitization and Action - A Circular Model
}

\author{
Emmanouil C. Kyriazakos \\ University of the Aegean, School of Humanities, Rhodes, GREECE
}

Received 10 September 2019 • Revised 2 December 2019 • Accepted 10 December 2019

\begin{abstract}
Undoubtedly, music is an integral part of everyday life and has been an important factor in education, expression, and influence since antiquity. The ultimate goal of our research was to explore the current relationship of artists with the environment, the influences they receive, and whether projects with similar content can sensitize listeners to environmental issues. The majority of Greek artists believe that the relationship between music and the environment is still strong, although it seems to be waning year after year. The living environment is a source of inspiration for creation and they believe that songs, combined with some factors, can sensitize the world and lead it to adopt appropriate behaviors and actions in the context of sustainable development. This has the effect of forming a circular environmental feedback model through the artists, their works and the listeners.
\end{abstract}

Keywords: music, environment, artistic creation, environmental sensitization.

\section{Introduction}

\subsection{The position of music in Ancient Greece}

In ancient Greece, they believed that the gift of music was of divine origin and that it was a gift of the Muses to the people (Neubecker, 1986). Moreover, teaching music was one of the three basic lessons of youth education and it was of significant importance to qualify for someone educated or not (Kaimakis, 2005). It is no coincidence, the multitude of philosophers who dealt with the native value of music and studied its effect on humans (Sxiza, 2008). Plato, typically, believed in the power of music and claimed that it is divided into good and bad, according to the moral elements it contains. So, with the same ease, it could be either beneficial or dangerous, for the smooth functioning of society, but also of the state in general (Kaimakis, 2005; Garofalo, 2010). In addition, Pythagoras believed that music had healing properties and claimed that the universe works with the same harmony as music (Bowie, 2009).

\subsection{The "power" of music}

German composer Richard Wagner said that "when the power of words end, the power of music begins" (in Sakellaridis, 2012: 66). Both music and song is information that, under certain conditions, can become the person's property, influence him or even change his behavior (Abercrombie, 2000).

(C) Authors. Terms and conditions of Creative Commons Attribution 4.0 International (CC BY 4.0) apply. Correspondence: Emmanouil C. Kyriazakos, University of the Aegean School of Humanities, Michael Petridi 2 str., Rhodes 85133, GREECE. E-mail: kyriazakosm@gmail.com. 
The view of the British ethnomusicologist and social anthropologist John Blacking (in Holst, 2014: 23) is that it is not good enough for a composer just to write good music but the music must be composed to unite people. Music composer Mikis Theodorakis says that music can change a whole society (Ibid.) and the music critic Simon Frith (in Small, 2010: 322) wonders concluding that since a branded artist brings enthusiasm to fans, why not have an influence on them too? Besides, the phenomenon is often observed, whenever something convulsed the global public opinion and needs a rallying of the world to cope with the difficulties, music and its representatives are the ideal solution for promoting the goal, since artists have a lot of influence because of their recognizability. Something similar can also be used in the spread of volunteering (Bıçakçı, 2013).

A typical example is rock music from the ' 50 s to ' 80 , managed to bridge the differences and bring people together. Many wonderful songs have helped publicize and publicly express the problems of society such as war, oppression of the peoples, racism, gender equality, as well as the liberalization of views on some "taboo" issues, such as sexuality or treatment of AIDS patients (Hesmondhalgh, 2013). The socio-religious restrictions that existed until then, received a powerful blow from the artists where they freed their messages through the lyrics of their songs. The gathering of their listeners around the global problems was such that, they were able to overturn political and social issues (Small, 2010).

On the white social canvas, which the musician creates, the artistic expression is helped by the experiences, the worries, and concerns of the creator. Guitarist B. B. King reports that any emotion he felt, he tried capturing in the music he played on his guitar, so, he tries to make his guitar sing for him and to convey those feelings to the listeners (Justin \& Timmers, 2010).

Generally, music can shape the public opinion and lead people to be sensitized, resistant, demonstrative, and even press politicians to find solutions to various social problems. All this was expressed through the songs that were written and called "protest songs" as they were heard in demonstrations and organized gatherings (Grigoriou, 2011).

For Small (2010), an artist, a song must be written to be able to influence the listener and not just be a simple presentation by the musician or singer. After all, through a song, a special relationship of interaction and messages are created between the musician and the listener, a desirable relationship, because a good musical song can cause various emotional states to the listener.

\subsection{Music, psychology and emotion}

Music and songs can meet the needs of composers and listeners to express their thoughts and feelings (Juslin \& Laukka, 2003). The relationship between music and emotion can be divided into three different forms of manifestation: representation, expression and causing emotions (Tsetsos, 2012). Besides, according to Bowie (2009), music is another form of emotional expression.

In general, music has the ability to convey, create and "awaken" emotions to the listener (Sloboda \& Juslin, 2010). To what percentage someone will be influenced depends on many parameters such as education, personality, temperament, social environment, cultural environment, even by the music or the song which someone listens to. This may be due to the particular features of each kind of music and depending on how it affects certain aspects of the psychosomatic existence of people.

Research has shown that the effects of music are more positive than negative. Most people feel relaxed entertained, and have fun, while a small percentage states that listening to 
music makes them feel anxious, aggressive and irritated (Zentner \& Eerola, 2010).

Factors that have an effect on psychology, apart from gender, age and educational level, include a multitude of variables, such as the physical state as well as various factors like expectations, sensitivity, positive or negative memories in relation to music, etc. Furthermore, how music influences psychology depends on the emotional state of the person at the time of listening. That's why the same piece can cause diametrically different emotions. Lastly, another factor that influences psychology is the physical environment such as if it is live or recorded music, where the listener is and his position at the moment, the season, etc. (Scherer \& Zentner, 2001).

\subsection{Music and education for the environment}

In environmental education, it has been prevailed that it is better approached through emotions and generally through art because it engages the learners creatively during the learning process. For example, in the context of an environmental education program, music would be a driving force for students' interest in acquiring knowledge, skills, and abilities, as well as lead them to the manifestation and activation of their creativity (Papavasileiou, 2011).

Music as an art has the power and can have a decisive and catalytic role in the emotional cultivation and sensitization of students on environmental issues (Sakellaridis, 2012). In most cases, when music is a teaching tool it can be used to maintain or increase student interest in a subject, gives a powerful motive for a teacher to speak in the classroom about the real world and is an important source of historical and geographic information which is provided through the lyrics (Ramsay, 2002). That's why the music in the teaching process must be pleasant and satisfy the interests and needs of the students (Dervisis, 1998).

The kind of music that has praised the beauty of the environment and its value in life is the folk song, as it often contains elements of nature. Through the folk song, the unknown creator "testifies" his concerns, shows respect and his need for the harmonious coexistence between people and nature. The fact that more people have come in contact with folk song and tradition, this informal experiential learning form of environmental education, makes an ideal way of contributing to the environmental awareness in the local communities and with the appropriate information and motivation can lead them to become volunteers or even act as independent teams for the protection of the local natural environment (Papavasileiou, 2011).

\subsection{Artistic inspiration and environment}

For many artists, the environment is a source of inspiration and creativity, and that's why environmental problems do not leave them untouched, instead, demonstrate their sensitivity in practice, either in their works or in their statements (interviews, announcements in social media, concerts). Therefore, it's logical to be easier for them to reach out and mobilize the listeners' feelings about such issues (Polychroniadou-Prinou, 2003). In the past, many wellknown artists such as Michael Jackson, Cat Stevens, David Bowie, and many bands such as REM, U2, Pink Floyd, Radiohead, have played songs explicit for the protection of the environment, climate change, etc.

As Aggelikopoulos says (2010), listening to the songs of every season, we can perceive the dominant tendencies, as well as the "worries" of the creators. A lot of artists create works for mobilizing public opinion. Having shaped their own personal attitude and sensitivity to an issue, they influence other people to adopt similar behaviors (Zisis, 2009).

In the case of a beautiful place, when this image is accompanied by an attractive composition, the whole performance is experienced and printed with greater intensity in the 
memory. In this situation, music, which is an independent stimulus, generates euphoria and generally positive emotions, resulting in the environment where the event takes place, becoming more accessible, intimate and ultimately beloved (Kokkinaki, 2006).

The influence of music, in addition to everything else, is also mental. How many times has a synthesis helped us think about a solution to our problems or relax us from the stress of everyday life (Cook \& Dibben, 2010)? All this shows that it is linked to the person's feelings and mood (Hesmondhalgh, 2013), although it is not sure that it will affect all listeners in the same way (Sloboda \& Juslin, 2010).

The process of completing a song or composition consists of two parts: the inspiration and creativity. Inspiration is the element that will affect the artist and will push him into the desire to write what he sees, hears, and feels, in the music and the lyrics. While creativity is the ability of the artist to be able to perform in a unique and original way so the listeners will be able to make it their own. In fact, the artist experiences this in his own imaginary world. There he creates and expresses himself, without this meaning that his world is a perfect world. Besides, he has the "ease" to constantly change his world and improve it (Sakellaridis, 2012).

Creators, no matter how lonely they are or seem to be, are members of a society in which they participate, collaborate, exchange opinions in open discussions, react, dispute and conflict. But they are receptive and let their imagination go free to create whenever and whatever they want (Xanthakou et al., 2015), and this can trigger someone else to create something even better. In this magical world of creation, which has no beginning and end, there is a chaotic and ongoing interactive relationship between the artists and the environment.

\subsection{Music and environment: A "dependent" relationship \\ that is worn out as years go by}

In today's age, music is everywhere and connected to all the moments of our daily lives (Hesmondhalgh, 2013). Listening to the radio in the car as we go to work, at any store to buy a product, when we relax while watching TV or when having fun at a bar or concert. The reactions to musical stimuli diversify from person to person and depend on factors such as the personality, level of knowledge, culture and personal music experiences of each listener (Sloboda \& Juslin, 2010).

For Small (2010) it is important both what the artist chooses to create and what the people choose to hear. This explains the reason for the separation of different kinds of music and the "identities" that the listener accepts or not. Every participation in a musical act expresses a need to manifest where someone belongs or wants to belong, that is to state the relationships that he wants and which are ideal for him. According to Hesmondhalgh (2013), people are now communicating through this art. There are various "music societies", without borders, ready to welcome anyone who wants to express themselves and communicate through music.

The human relation to music is twofold: as an object of viewing the musical work to the listener through the creator-performer and as an object of identifying the listener with the musical work, mainly in behavioral matters, which also depends on the psychology of the listener at the specific time (Polychroniadou-Prinou, 2003).

Today, art and especially music does not have the meaning and function it once had. The huge and global commercialization, coupled with the evolution of technology and especially the internet, has the effect of writing simple songs or music compositions, without a creative mood for projects that raise public awareness of a social problem (Hesmondhalgh, 2013). Small's view (2010) is that the relationship has changed, from consent it has been converted to dominant. For producers, in the broad sense of the term, music, and song are "products" that if used 
appropriately will bring them more profit (North \& Hargreaves, 2010).

Concerning the role of the media nowadays, many of them, using music and its psychological impact on viewers, are "constructing" a reality seeking to manipulate the population. The so-called "objective information" leads to social apathy and social "blindness" from the real problems, which most of them are directly related to the environment. In fact, the media has become a "weapon" of propaganda by those who exploit the planet and music has become the fancy garb of messages "buy everything, because you have the need for them" and "sleep peaceful because everything is going well" (Grigoriou, 2011).

As far as environmental issues, the majority of the media presents humans as the ruler of nature, on the contrary, nature is presented as an enemy of humanity and as something that restricts and in many cases threatens people's life. As a result, humanity is turning to anthropocentric perceptions and decisions, while its universal attitude is to address the general environmental problems with apathy. Exceptions to the rule include some media that, through broadcasts and documentaries, promote the value and beauty of the environment (Zisis, 2009).

In fact, the relationship between music, human and the environment has changed. It has become more neutral and indifferent. The fact that music is everywhere, has influenced people to stop listening if they don't want to (Papazaris, 1999) and of course, music has lost its social identity, its value and its important place in society.

\section{Method}

\subsection{Research tool}

As a research tool, we used the semi-structured interview, to allow us flexibility in supplementary questions formulated based on specific guidelines cited in the literature. (Robson, 2010).

The method of purposeful sampling was selected for practical and financial reasons. Given the sampling method, the results of the study cannot be generalized, which however are not in the pursuit of qualitative methods in general. The interviews were conducted in Rhodes, Greece, from June to September 2016.

The research was based on the idea that music as an art can contribute to the achievement of the environmental education goals and was conducted in order to register the views of artists on the relationship between the environment and their creative expression and whether environmental awareness among the listeners is achieved through the artworks.

Our main research questions were:

(1) What is the relationship between artists and the environment and how does it affect their psychology and their work?

(2) Do artists believe that there can be environmental sensitization of the world with the music and songs?

\subsection{Participants}

The research sample consists of twenty-three (23) Greek artists who are professionals in the field of music. Their average age is 41 years, with the youngest participant being twenty-one (21) years old and the oldest sixty-nine (69) years old.

The relationship of the majority of participants with music is multifaceted. Many of them have many capacities and capabilities, such as to be a musician and performer at the same 
E. C. Kyriazakos - Music and Environment: From Artistic Creation to the Environmental...

time. In the same way, many are occupied in more than one kind of music. So, in the whole sample, twenty (20) are musicians, fifteen (15) are performers, twelve (12) are composers and ten (10) are lyricists. Correspondingly, the kind of music which they are dealing with, are: nine (9) with rock music, six (6) with traditional music, five (5) with folk music, four (4) with artistic singing, four (4) with rembetiko, three (3) with pop music, three (3) with jazz music, three (3) with heavy metal music, three (3) with classical music, two (2) with blues music, two (2) with ethnic music, one (1) with electronic music and one (1) with Byzantine music.

\section{Results}

\subsection{Relationship between music and environment}

Most artists believe that there is a strong and enduring relationship (73.9\%) between music and the environment, expressed musically or lyrically through songs. In their view, they support that attitudes and values are promoted: "Music and art, in general, are holistically linked to the environment. Targeted music actions promote the acquisition of appropriate attitudes and values regarding the importance and protection of the environment" (Interviewee 1), that the emotional connection of the audience with the environment is strengthened: "As a global language, it can diffuse to everyone and raise awareness of the environmental problems" (Int. 2), "Through music, anybody can spread a message and raise awareness of some situations" (Int. 10), "Singing is one of the best ways to raise awareness of environmental issues" (Int. 17), that it is an interactive relationship: "The environment-human relationship has been and will remain a dynamic balance" (Int. 23), "A musician who respects his music, has to respect the place he lives in. Also, music has lost its natural origins and its magic" (Int. 3), that is an inspiration for creation: "The environment is a great inspiration for music, it acts decisively on what sounds we will need to play and what lyrics we will want to sing" (Int. 11), "Many of the works we see are inspired by natural phenomena or the environment" (Int. 19), that it manifests through certain kinds of music: "Important songs have been written [in rock music] that show that there is awareness" (Int. 6), "There is a connection with the traditional song. People lived in the countryside and what they saw is what they were sang" (Int. 14), "Folk music has praised nature more than any other kind of music" (Int. 15).

On the contrary, about one in four participants (26.1\%) thinks that there is no relationship today: "There is no relationship at this time. There was a time in the '6os and' 7os, where there was generally a great love for nature which has been expressed through music" (Int. 7), "I don't think there are enough songs that deal with the environment and its problems" (Int. 8).

The views of the concerned artists on what should or what they would want to change in the relationship between music and the environment, highlight the need for environmental organizations to become more active: "Organizations should showcase music that will affect the world. Pictures combined with music" (Int. 12) and the voluntary effort on the part of the artists: "Those of us who will participate at a concert to raise awareness unfortunately are very few. However, there could be more artists" (Int. 17).

\subsection{The environment as a source of inspiration for artists}

After analyzing the artists' responses, the majority of them responded that the environment is a source of inspiration to create (78.3\%), while only $21.7 \%$ answered negatively.

As to the ways in which they are affected by the environment, several interviewees referred to the natural and anthropogenic environment: "I work with images" (Int. 3 \& Int. 5), "There is a creator's need to be in a [beautiful] place to write or compose" (Int. 4), "In my mind 
I picture the tree, the flower, the mountain" (Int. 8), "The concept of the environment is very broad. People and different places are sources of inspiration" (Int. 2), "Your source of inspiration differs when you write in the city, at the mountainside or in a forest. Not that you produce a different quality but your motivation is your surrounding" (Int. 6), "In order to be creative, you are stimulated by nature and the things you experience" (Int. 7).

There were opinions from interviewees who stated that their living environment, creates the appropriate mental state and they translate it into creativity: "It is the mental and physical condition that brings you to the environment" (Int. 11), "Inspiration is like opening a door and communicating with God, where God is nature and we are one" (Int. 16), "It gives you seeds so you can plant a tree" (Int. 17), "With peacefulness and calmness" (Int. 19), "Sometimes I can be somewhere and the whole scene is amazing... you feel awe in front of nature and the vibrations of the space" (Int. 22).

Interviewees who had a positive response and would like to create or participate in a song for environmental sensitization were slightly more (56.5\%) than those who were negative $(43.5 \%)$.

As for the artists who responded affirmatively, have already done so in the past: "I could rewrite. Fantastic things can be written about it [the environment]" (Int. 12), "Yes, I interpret it in every opportunity that comes across in the course of my career" (Int. 23) and some have expressed a willingness to write a song about the environment or to participate in the composition: "I could. Either way, when I compose, I'm not composing for the environment but composing from the environment" (Int. 18), "I would be happy to participate in a composition" (Int. 19). For some interviewers the idea of writing a song about the environment, see it as an opportunity to get a message across to the people: "We have to first compose a song to unite the artists, in order to send the message" (Int. 17).

On the contrary, artists who were negative to create or even participate in such acts expressed the view that they don't write or participate in "targeted" songs, as they described them: "I was never positive about targeted songs" (Int. 3), "The truth is, I never write targeted" (Int. 20).

However, there was also one artist who mentioned the factors that worked negatively against him in making his work go public: "I have written a song about the environment and it was not approved by the record company probably because it wouldn't sell... maybe, if I were well known, they wouldn't even bother at all..." (Int. 12).

\subsection{Sensitization through music}

Regarding the question whether songs or compositions can lead the world to environmental awareness about environmental problems, 60.9\% of the respondents answered yes, 34.8\% answered negatively and only $4.3 \%$ did not answer the question.

Of the participants who responded negatively, that is, those who do not believe that one can acquisition environmental consciousness through music or song (34.8\%), most note the human factor, education, and generally behavior: "If he does not make an individual effort in his living space, then what can we say that he will do? Behavior in the environment begins with each person individually" (Int. 3), "I think that environmental awakening is not the primary goal for the people who attend concerts" (Int. 7), "From the artists" point of view who write these kinds of songs, yes, there is. But there is no effect" (Int. 8), "Unfortunately, the world's sensitization no longer depends on the composer" (Int. 12), "If a Greek does not live in an area which is being threatened to become a landfill, he doesn't care" (Int. 13), "I don't think that people depend on songs in order to become environmentally sensitized" (Int. 14), "If used alongside 
E. C. Kyriazakos - Music and Environment: From Artistic Creation to the Environmental...

verbal and image content, then yes, it can play an important role. One song, on its own, cannot sensitize you" (Int. 18).

On the other hand the artists who answered that music can make people more aware (60.9\%), cited environmental issues: "Their view on environmental problems is affected, and are encouraged to actively participate in addressing them" (Int. 1), "Songs make a problem known with the hope to entice a group of people to do something about it or to protect it" (Int. 4), "[influences] Indirectly, through the lyrics and mainly locally. To bring the listener a little bit into the status of the creator, in his day-to-day life" (Int. 22), "I have been involved in musical performances and children's books that raise children's sensitization on air pollution, the sea and the protection of forests and rivers" (Int. 23). Several interviewees referred to the power of music, which can motivate people in all directions, and therefore the environmental sensitization, "Depending on how the soundtrack is positioned, if properly positioned, it will also make you fall in love with the environment" (Int. 9), "I truly believe in the role of art... a song makes our day beautiful, it makes us love, respect... our environment, our space... it is a power that helps at all levels" (Int. 11). Views were also recorded regarding the role of music in the educational process: "A remarkably eco-friendly song can serve educational purposes" (Int. 2), and the impact of music on the emotional world of people: "Music has an emotional impact on people, it creates an atmosphere to bring people closer to a purpose... to convey a message either through lyrics or even in sterile speech" (Int. 21).

\subsubsection{Songs with environmental content and audience ages}

Artists were asked to try to determine the ages of listeners who listen to songs or music compositions with environmental content. The interviewees' views were quite diverse and extensive. Responses were categorized for convenient reasons and the results (percentages) of the listeners' ages that listen to songs with environmental content are presented below (Figure 1):
1) (o-6 age): Newborn-age
2) (7-12 age): Childhood
3) (13-18 age): Adolescence
4) (19-30 age): Young people
5) (31-50 age): Adults
6) (51-64 age): Middle-aged
7) (>65 age): $\quad$ Elders

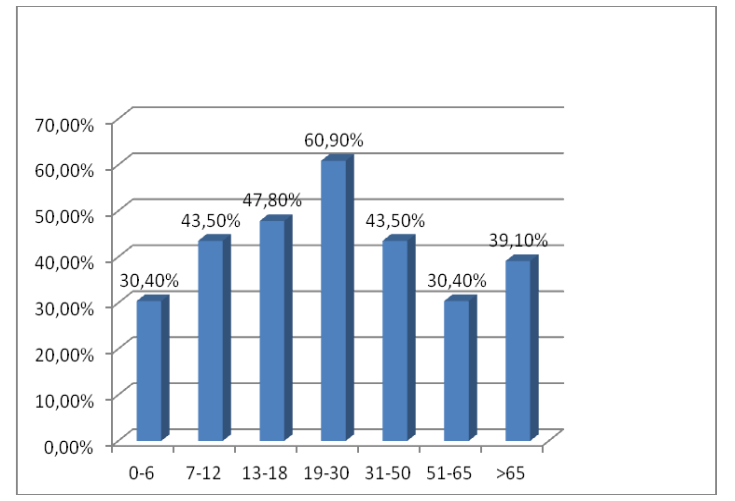

Figure 1. Percentage of listeners to songs with environmental content

Specifically, some artists responded that age does not play a role when listening to 
songs or compositions with environmental content, "Everyone could listen to a song about the environment" (Int. 9), "It has nothing to do with age, but with people's culture” (Int. 11), “Age doesn't matter. The issue is not who listens but who is really paying attention to the message the artist wants to get across" (Int. 20).

Some believe the proper age is infancy and childhood: "We need to let children know about these issues. A little song could work in the right direction" (Int. 21), "Children's songs are geared towards education. They talk about the environment, behavior, respect... I think that they are at the right age to learn about appropriate environmental behavior" (Int. 12). Most artists mentioned that people in their teens and youth are the ones who mostly listen to such creations: "Such issues are often dealt with by a student because they have the luxury of time" (Int. 19), "15-25 years old. I see a lot of kids starting to get emotionally attached to the environment" (Int. 17), "Those who actually realize and essentially address the issue, I think are ages 25-45" (Int. 6), "After the age of 20, young kids who want to get into production only find a dead end" (Int. 16), "25-35. Are the ages that still have no responsibilities" (Int. 8), "25-35. These ages are best suited to raise awareness of the issue. They have the responsibility within them" (Int. 10), "30-50. They become more aware and understand a problem exactly as they should" (Int. 4). Views were also recorded that consider middle-aged and older people as those who listen to songs about the environment more than other categories, "It's certain that if a Beatles song was heard from someone born in the 40's it would trigger memories and even get them excited".

There were $13 \%$ of respondents who answered that no one listens to songs or music compositions with environmental content, mainly because they think there are no such songs: "Is there anyone who wants to hear songs specifically about the environment? I think people want to hear specific kinds of songs... if there are any environmental issues included in them, okay..." (Int. 14).

\subsection{Influence of musical works and volunteering}

Only $13 \%$ of respondents say that their psychology is not affected when listening to a song or musical composition about the environment. $43.5 \%$ state that if they are affected depends on a variety of factors and the same percentage (43.5\%) is affected in different ways.

As for the artists who stated that their psychology is influenced when listening to creations with environmental content (43.5\%), most consider them to be emotionally affected: "I am affected cognitively and emotionally" (Int. 1), "I'm glad to hear such efforts" (Int. 3), "All artists have antennas that are a little more sensitive... we experience things a little differently, we deeply grieve..." (Int. 16), "Sometimes with sadness about the change of ecology in places that are described in some songs, other times with joy and delight for music and songs that celebrate the beauty of the environment" (Int. 23). Some artists are psychologically influenced by listening to environmental content songs, "It will guide me... I have been greatly influenced by music and shows" (Int. 12), "I'm trying to be at the place which the song describes. I would try to imagine the whole scene" (Int. 14). However, one interviewer argued that the change of the psychological state when listening to music with environmental content is temporary, "Psychology is affected, but it's only for a moment, it is temporary" (Int. 9).

Many interviewers are emotionally affected by songs and music compositions; however, some conditions are necessary. A key prerequisite is the quality of the music and the interpretation, "It depends. If I hear something beautiful, it will make me enjoy it. On the contrary, if the song is depressing, it will ruin my psychology and make me sad" (Int. 4), "My psychology is influenced by the part of the music. If the music annoys me, I may not even hear the song. If it touches me musically, it will make me more aware" (Int. 5), "It depends on how the artist will interpret it... if it triggers my imagination, I'll be excited and I'll get up from the chair" (Int. 17), "I don't know if it will affect me 
positively or negatively... if the track has a musical interest, it will spark my interest and I will like it" (Int.18), "It depends on the composition and how successful it will be in making me aware... Maybe I will be sensitized but the message which is trying to get through will not become my lifestyle or it may change the way I think about specific issues" (Int. 19), "It depends, if the music is not good, I'll ignore it... the process hurts me psychologically and it causes me a feeling of nostalgia because Iforget myself in the urban environment" (Int. 21), "I think it has a lot to do with the creator, if he sounds convincing and if he can convey it" (Int. 22). Also, for some artists to be influenced emotionally find that the message theme of the song is important: "It has to do with the person who writes the song and if he takes it seriously" (Int. 7), "It will be less important to me, If I am already suspicious that the song is targeting on environmental issues" (Int. 11).

However, there were artists who said that they are not affected emotionally if they listened to a song or a musical composition, "I'll be very honest... we think about it at the time we hear it and then we forget it" (Int. 8), "The difficulty for most musicians is that we have a lot of things to look at in a song... it's hard to say that it touched me" (Int. 20).

Many artists believe that listening to a song or music composition with environmental content could lead to voluntary action, and most of them, consider it as an obligation: "Of course it could. Revolutionary music, against the system, takes people and classifies them against the system. You can do anything with music as long as you have a target and a purpose" (Int. 12), "Wherever I am called, I will go. I'm trying to do something, at least" (Int. 17), "Of course it can sensitize me. But the fanaticism is dangerous... because you can act effectively but you are not impartial" (Int. 20), "We have a debt to fight for the common good and a wakeup call... to save whatever we can and enjoy the gift of life" (Int. 15).

Some interviewers are negative on the thought of volunteering and this is attributed to a variety of factors. Some have mentioned that once they are involved in music, they have to be able to offer from this position: "Whenever I am called to help, I've done many times and I'm glad. I think my help is mainly through my music and my lyrics... I help some people in my own way" (Int. 3), "We have a debt through our music to open people's souls" (Int. 16), "I believe that as an artist, my role is to be wherever they are calling me" (Int. 6). Some participants responded that by listening to songs or music compositions they felt that it was not enough to be motivated and to be led to volunteer: "It's a bit difficult for me to suddenly change because I heard a song about the environment and to start saying that I'm going to be in an organization to do something about the environment" (Int. 9), "I can't all of a sudden become another person because I hear a song" (Int. 10), "It's difficult to happen with just one song. A person needs to be persuaded to get to the point of actively volunteering" (Int. 19), "I feel it's difficult to make it happen, to be sensitized on environmental issues because of a song. It can work, it can help...just a few...” (Int. 21).

Finally, there were views of artists who did not exclude the possibility of volunteering by listening to a song or a musical composition, but there were some prerequisites for doing so: “...if l feel the need to serve exclusively in this field, then I'd fight for it" (Int. 6), "If the track is affecting me emotionally, maybe I could join an organization" (Int. 8), "Probably. It cannot just be out of nowhere. There has to be an inner preparation first for everyone" (Int. 22).

\section{Discussion - Conclusions}

Today's citizens must realize their cultural identity, otherwise, they will not be able to keep it intact, preserve it and pass it on to future generations (Papavasileiou, 2015). In this context, in the battle for the promotion of Environmental Education, art, beyond its involvement in the environmental movement, it must become part of it (Flogaitis, 2009), because a human reacts to art's stimuli, it fills his imagination, makes him dream of a better and more beautiful world, as well as, becoming more creative. At the same time, through music, listeners are 
emotionally and psychologically connected to areas of natural beauty and mobilized to protect and preserve them whenever needed.

According to Mikis Theodorakis (in Sakellaridis, 2012), the musician is influenced by his day-to-day life and the social events which he attributes to his work. Small (2010) believes that music experiences can broaden the public's understanding on certain issues and make them see the world from a different perspective.

Music and songs have changed societies, uniting people with common visions and ideals. Something similar has been done with the environment. Artists are inspired by the environment, the elements of nature and through their personal experiences. Many songs have been written with ecological content, songs of protest or even indignation. There are global but also local examples where music has contributed to changes, ranging from perceptions and social stereotypes, to even political overturns of both legislation and political philosophy.

The environment is a place of inspiration and expression for artists and accordingly affects their psychological mood. In song and music we understand the stimuli that the artist receives from the environment, as well as the emotions he feels through this interaction. So, it goes without saying that these feelings are "channeled" to the listeners and make them feel the same (Sloboda \& Juslin, 2010). That's where the power and value of music can be seen. That is exactly what Plato meant when he said that music can do both good and bad in a society. Because, besides everything else, music also has moral values (Kaimakis, 2005).

In his latest interview, Russian composer, pianist and orchestra director Sergei Rachmaninov, had mentioned: "My incessant desire to compose music is an intrinsic urge to express my emotions, such as speaking to express my thoughts... Study the masterpieces of the great composers and you will find every aspect of their personality and their environment in music... Time can change the techniques used in music, but it will never change the mission of music...”(in Diamanti, 2017).

The aesthetic of a musician is definitely related to the aesthetics of the environment, after all, the environment is the artist's "muse". Obviously, the alteration of the natural environment is the one that affects them the most, because it's something they experience every day (Kyriazakos et al., 2018).

The results of our research show that the majority of artists believe there is a profound and significant relationship between the environment, music and songs, but it has been declining over the decades. The environment is an important influence and creates the right conditions for artists to feel the need to express themselves through their work. They also believe that music and songs have the power to direct people towards environmental sensitization, with the ultimate goal of actively engaging citizens in solving these problems. On this basis, they state that they are more aware and responsible because of their social status and recognition. The emotional state of artists is either affected positively or negatively when listening to songs or music with environmental content, but a significant proportion, mostly pays attention to the quality of the song, musically and interpretively. Lastly, the volunteering part does not excite all artists. Although many interviewees feel that they have to offer physically, some believe that it is better to offer through music and songs.

Studying the relationship between music and the environment-creator-listener triangle, we observe that there is an interaction and interdependent relationship. The environment directly or indirectly affects humans (creator or listener) and people correspond either by praising the beauty of the environment (if it is a creator) or by trying to preserve that beauty (listener). The music and lyrics, as well as their representatives (creators-artists) as communicators with the "receiver", are the three main pillars that can contribute to this purpose, 
in raising public awareness. In a simple four-step schematic illustration we could analyze it as follows:

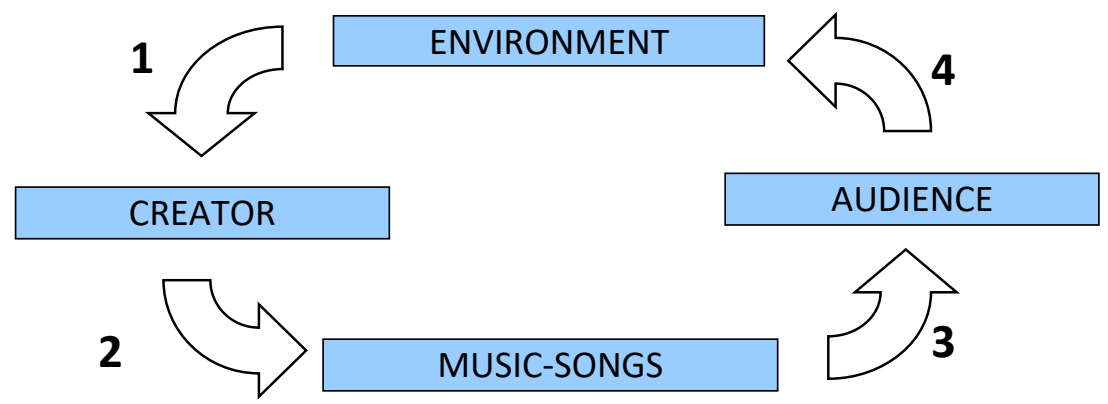

(1) The environment (dynamic environment) is the inspiration for the artist (environmentally dependent creators);

(2) The artist creates his works (musical compositions, songs) with environmental content (musical variables);

(3) Final projects (musical compositions, songs) are promoted to the public (musically dependent targets);

(4) Listeners are being sensitized to environmental issues and are active in protecting and resolving problems (new dynamic environment).

For relationship \#1: every creator is affected differently by the environment. Basically, in any environment (in the broad meaning of the term) its interaction with a creator, two cases may apply: a. the environment to be "neutral", that is to say, the environment experienced by the artist is completely indifferent and therefore useless, non-creative and b. the environment to be "creative", that is, to influence the psycho-synthesis of the artist-creator, positively or negatively, which can be directly or indirectly led to the creation. Many times, this environment works the least but additively to it. How quickly the artist will be affected depends on many factors, such as how strong the emotions which arise in the artist are from his experiential relationship and observation, his earlier experiences and the need for expression (creation). On the contrary, time (as duration) plays no role at all. The artist can create a complete piece of work by photographing a moment in the environment or observing it for years.

For relationships \#2 and \#3, a major role is played by the result of the previous relationship (creation until it reaches the listener): A song is subject to change many times before its journey reaches the audience (goal). The creator can redefine his work, depending on the response. Usually, before its final form, it goes through a "pilot" test, that is, exposes the result to small target groups such as friends, demos, music producers, etc. If the result does not satisfy the artist, then he abandons it or, he redefines his work. If the result has a positive impact (public reception) then he proceeds to output (production).

For the relationship \# 4: The difficulty lies in convincing listeners about the purpose of the project, in this case, to make the world more sensitive to the environment. The listener as the receiver filters the project's message-information, which affects him or not accordingly. Decisive factors of the outcomes effort is the corresponding environment in which the listener receives the information, the situation in which he is in, the additional influences he receives from related projects, experiences or relationships with other social groups.

Although the relationships in the diagram above are simplified, confessedly "convincing" the world is a difficult doing part and is dependent on many factors. In many cases, 
the involvement of the creator with statements or active participation, can help and contribute. It would be a big mistake to say that change came exclusively from music, but we cannot exclude its involvement in social influence for decision-making and action. The desired situation results in a "new" dynamic environment, repeatedly following a spiral relationship.

In conclusion, arts such as poetry, dance, and music need to play a leading role in education. They contribute to raising awareness and creating responsible and active citizens who love the environment, respect it and work to protect and preserve it, so they can deliver it, possibly even better, to future generations, thereby meeting the species' intergenerational needs. Music has the power to bring together individuals and make a collective change, for a society with principles and values in the interests of present and future generations. What we really need are new perceptions and solutions that ensure sustainability in a new world of values (Tzaberis et al., 2014).

\section{Acknowledgements}

This research did not receive any specific grant from funding agencies in the public commercial, or not-for-profit sectors.

The author declares no competing interests.

\section{References}

Abercrombie, M. L. J. (2000). Creative teaching and learning: the anatomy of thought (E. Mpakalaki, Trans.). Athens: Gutenberg. (in Greek)

Aggelikopoulos, V. (2010, July 17). The environment in the Greek song. Eleftherotypia. Retrieved 18 January 2017, from http://www.enet.gr/?i=news.el.article\&id=183424. (In Greek)

Bıçakçı, A. B. (2013). Creating Public Environmental Awareness through Music: "Play for Nature” Project. $1^{\text {st }}$ Annual International Interdisciplinary Conference, 24-26 April, Azores, Portugal.

Bowie, A. (2009). Music, philosophy and modernity. New York: Cambridge University Press.

Cook, N. \& Dibben, N. (2010). Emotion in culture and history: perspectives from musicology. In: P. N. Juslin \& J. A. Sloboda (eds.), Music and emotion. Theory, research, applications (45-72). United Kingdom: Oxford University Press.

Dervisis, N. S. (1998). Creative thinking and creative teaching process. Thessaloniki: Maiandros. (In Greek)

Diamanti, M. M. (2017, March 28). Sergei Rachmaninoff: Music is enough for a lifetime, but a lifetime is not enough for music. KLIK Magazine. Retrieved 20 April 2017, from http://www.klik.gr/gr/el/prosopa/sergkei-rachmaninof-piano-pianistas-magika-cheria-kontertotsaikofsku-ergografia/. (In Greek)

Flogaitis, E. (2009). Experimentally exploring a fruitful relationship: Environmental education and art. $1^{\text {st }}$ Greek Conference of Art \& Environmental Education: Art as a training tool for the environment (131-134). Athens, 29-31 May 2009. (In Greek)

Garofalo, R. (2010). Politics, mediation, social context, and public use. In: P. N. Juslin \& J. A. Sloboda (Eds.). Music and emotion. Theory, research, applications (725-754). United Kingdom: Oxford University Press.

Grigoriou, M. (2011). Music perception and creation. Universal constant and cultural variables. Athens: Nefeli. (In Greek)

Hesmondhalgh, D. (2013). Why music matters. Oxford: John Wiley \& Sons, Ltd.

Holst, G. (2014). Theodorakis: Myth and politics in modern Greek music (S. Kraounakis- L. Tsirimokou- E.A. Vris, Trans.). Athens: Metronomos. (In Greek) 
E. C. Kyriazakos - Music and Environment: From Artistic Creation to the Environmental...

Juslin, N. P. \& Laukka, P. (2003). Communication of emotions in vocal expression and music performance: different channels, same code? Psychological Bulletin, 129(5), 770-814.

Juslin, N. P. \& Timmers, R. (2010). Expression and communication of emotion in music performance. In: P. N. Juslin \& J. A. Sloboda (Eds.). Music and emotion. Theory, research, applications (453-489). United Kingdom: Oxford University Press.

Kaimakis, P. (2005). Philosophy and music. The music of the Pythagoreans, Plato, Aristotle and Plotino. Athens: Metaixmio. (In Greek)

Kokkinaki, F. (2006). Social psychology: Introduction to the study of social behavior. Athens: TypothitoGeorgos Dardanos. (In Greek)

Kyriazakos, E., Stavrou, N., Tzamberis, N. \& Papavasileiou, V. (2018). Music and the environment: a harmonious relationship. Views of Greek artists on environmental issues and sustainability. In: V. Papavasileiou. N. Andreadakis, I. Papadomarkakis \& M. Kaila (Eds.), Sustainability, sustainable development, nature and human nature. Our world; Quo vadis? (243-257). Athens: Diadrasi. (In Greek)

Neubecker J. A. (1986). The music in Ancient Greece (M. Simota-Fidetzi, Trans.). Athens: Odysseus. (In Greek)

North, C. A. \& Hargreaves, J. D. (2010). Music and marketing. In: P. N. Juslin \& J. A. Sloboda (Eds.). Music and emotion. Theory, research, applications (909-930). United Kingdom: Oxford University Press.

Papavasileiou, V. (2011). Environmental education in the education sciences. Athens: Pedio. (in Greek)

Papavasileiou, V. (2015). Sustainable Development and Education: The multidimensional relationship. Athens: Diadrasi. (In Greek)

Papazaris, T. (1999). Music learning and education. Athens: Papazisi. (In Greek)

Polychroniadou- Prinou, L. (2003). Music and psychology. Athens: Thymari. (In Greek)

Ramsay, D. (2002). The role of music in environmental education: Lessons from the cod fishery crisis and the dust blow days. Canadian Journal of Environmental Education, 7(1), 183-198.

Robson, C. (2010). Real-world research: A tool for social scientists and professional researchers (P. V. DalakouK. Vasilikou, Trans.). Athens: Gutenberg. (In Greek)

Sakellaridis, G. (2012). Music close to human. At school, in family, in society. Athens: Grigori. (in Greek)

Scherer, R. K. \& Zentner, M. R. (2001). Emotional effects of music: Production rules. In: P. N. Juslin \& J. A. Sloboda (Eds.). Music and emotion. Theory, research, applications (361-392). United Kingdom: Oxford University Press.

Sloboda, A. J. \& Juslin, N. P. (2010). At the interface between the inner and outer world: psychological perspectives. In: P. N. Juslin \& J. A. Sloboda (Eds.). Music and emotion. Theory, research, applications (73-97). United Kingdom: Oxford University Press.

Small, C. (2010). Musicking. The meanings of performing and listening (D. Papastaurou- S. Loustas, Trans.). Thessaloniki: Ianos. (In Greek)

Sxiza, K. (2008). Systematic thinking and environmental education. A didactic model that builds critical thinking and relationship with the "other". Athens: Christos E. Dardanos. (In Greek)

Tsetsos, M. (2012). The music in the newer philosophy. From Kant to Adorno. Athens: Alexandreia. (In Greek)

Tzaberis, N., Xenitidou, S. \& Mogias, A. (2014). The contribution of education for sustainable development in addressing ethical issues of climate change. ADAPTtoCLIMATE Conference. Nicosia, Cyprus, 2728 March 2014.

Xanthakou, Y., Kaila, M. \& Papavasileiou, V. (2015). "Imagination dead imagine” because "you can trap birds with birdlime, but you cannot capture their song". Athens: Diadrassi. (in Greek)

Zentner, M. \& Eerola, T. (2010). Self-report measures and models. In: P. N. Juslin \& J. A. Sloboda (Eds.). Music and emotion. Theory, research, applications (187-221). United Kingdom: Oxford University Press.

Zisis, I. (2009). Green bend. Volume Two. Green-ecological culture - environment and culture. Athens: Sustainability NGO “Solon”. (In Greek) 